\title{
International Commission on Zoological Nomenclature
}

Proposed fourth edition of the International Code of Zoological Nomenclature-a call for possible amendments to the third (1985) edition

The International Commission on Zoological Nomenclature has embarked on the preparation of a new (fourth) edition of the Code and has established an Editorial Committee for that purpose. It is expected that publication will be in late 1994 or in 1995. A considerable number of possible amendments to the Code have been suggested and these will be examined by the Editorial Committee. The Commission invites the submission of further possible amendments to the current (1985) Code and these should be sent as soon as possible to the Executive Secretary, I.C.Z.N., British Museum (Natural History), Cromwell Road, London SW7 5BD, UK. It is intended that proposals received by the end of 1989 will be discussed at meetings held in conjunction with the International Congress of Systematic and Evolutionary Biology (ICSEB) in Maryland in July 1990.

\section{Official Lists and Indexes of Names and Works in Zoology-Supplement}

The Official Lists and Indexes was published in 1987. This gave all the names and works on which the International Commission on Zoological Nomenclature had ruled since it was set up in 1985 up to December 1985. There were about 9,900 entries. In the three years since 1985, 544 names and 3 works have been added to the Official Lists and Indexes. A supplement has been prepared giving these additional entries, together with some amendments to entries in the 1987 volume. This supplement can be obtained without charge from the following addresses, from which the Official Lists and Indexes can be ordered at the price shown:

The International Trust for Zoological Nomenclature, British Museum (Natural History), Cromwell Road, London SW7 5BD, UK.-Price $£ 60$ or $\$ 110$. or

The American Association for Zoological Nomenclature, c/o NHB Stop 163 , National Museum of Natural History, Washington DC 20560 , USA.-Price $\$ 110$ (\$100 to A.A.Z.N. members). 